\title{
BIOLOGIZATION OF THE CULTIVATION OF MEDICINAL PLANT CAPPARIS SPINOSA L. IN ARID ZONES AND BIOTECHNOLOGY OF OBTAINING FOOD AND PHARMACEUTICAL PRODUCTS
}

\author{
Khamraeva N.T. ${ }^{1}$, Rabbimova F.T. ${ }^{2}$, Kubakova K.K. ${ }^{3}$, Matmuratova G.B. ${ }^{4}$ \\ 1,2,3,4 JizzakhState Pedagogical Institute, teacher \\ Corresponding author's email: nafisa.eshankulova@gmail.com
}

\begin{abstract}
A new biotechnology has been developed for the preparation of medicinal food products from the crop of capers (buds, flowers, fruits), canned food from enzymatically processed fruits, bread, using activated yeast, prepared from flowers and buds of capers. Adding capers Bud powder to the dough during kneading improved the fermentation activity of yeast, accelerated the maturation period of the dough, baked bread had a pleasant aroma, a large volume, ruddiness, porosity, and increased the shelf life of the finished product.

Practical recommendations are made on the use of pickled canned capers in the food industry. Protein components, vitamins, micro - and macronutrients and related valuable substances contained in prepared products were studied.

KEYWORDS: medicinal theroxerophyte, capers, products, fruit elements, products for the food and pharmaceutical industries.
\end{abstract}

Article Received: 10 August 2020, Revised: 25 October 2020, Accepted: 18 November 2020

If some 10-15 years ago we were new to olives, today this product is probably not inferior in popularity to green peas. Now it's time for new culinary discoveries. Take capers, for example. At first glance, they look like beans, but in fact they are miniature edible buds (less often - berries) of a perennial semi-shrub (lat.Capparisspinosa). You can find dried or pickled capers in stores. They are grown for sale in the Mediterranean region, the Middle East, Asia, North Africa, and California [Eshankulova N.T., Akhmedova Z.R., 2013]

Nutritional value of capers:This lowcalorie product is valued for its minimal cholesterol content, high amounts of protein and dietary fiber, and the presence of flavonoid antioxidants such as rutin and quercetin. These compounds have anticancer, analgesic, antimicrobial and antiinflammatory properties. In addition, the capers, there are other valuable substances: kaempferol, spermidin, stigmasterol, tocopherol, campesterol and carotenoids. [Inocencio C, Alcaraz F, Calderon $\mathrm{F}$, et al. 2002.]

1. Vitamin and mineral profile of capers: Vitamins A, C, E, Niacin, folic acid, and calcium, magnesium, iron, phosphorus, potassium, and selenium. The only dangerous substance in the canned product is sodium, the source of which in this case is the ordinary salt. A study conducted by Italian scientists proves that the antioxidants contained in capers help the body to neutralize the oxidative effect of meat digestion. It is the oxidative stress that causes DNA damage and an increase in oncological risks in the population
[Griffith V., 2002] Anti-cancer properties:Of specificinterest to scientists is the recently discovered phytochemical compound of stachydrin in capers, which has powerful anti-metastatic properties in the case of prostate cancer. It acts at the genetic level, preventing the growth and reproduction of cancer cells. This scientific discovery is a real breakthrough in the development of effective drugs against cancer. Aid in digestion being a rich source of dietary fiber, capers can improve digestion and normalize stools. They can also be used as an intestinal cleanser, which is of particular importance in the prevention of colon cancer. In southern Europe, capers have long been considered as a good remedy for relieving abdominal pain and fighting flatulence.[Inocencio C, Alcaraz F, Calderon F.et al. 2002]

Capers and blood pressure:It turns out that the extract of these berries relaxes blood vessels, so it is especially useful forpatients with hypertension. It serves to reduce excessively high blood pressure. Unfortunately, pickled capers are not suitable for heart therapy due to the excessive amount of salt they contain in 1 tablespoon, on average, they contain about $250 \mathrm{mg}$ of sodium. Also, a remedy against anti - atherosclerosis, arthritis and varicose veins due to rutin in capers, provides capillaries with strength and flexibility, it can be useful in the treatment of hemorrhoids and chronic venous insufficiency- a disease that leads to varicose veins, leg cramps and edema. In addition, rutin inhibits the oxidation of "bad" 
cholesterol and prevents its accumulation in the arteries. This antioxidant also has an antiinflammatory effect, thus helping in the treatment of arthritis. In the diet of diabetics, some of the chemicals found in capers help to lower blood sugar levels, so in theory they are also useful for diabetics. However, if you are already taking diabetic medications, you should not "catch up" with this Mediterraneanproduct: sugar levels can drop to dangerously low levels. Forstrongbones [Kan, Y.et.all, 2006, Vili A, Tao Wu, Sagdullaev B. T., 2006].

Beautiful skin and hair Surprisingly, caper extract is part of many elite skin care products: moisturizing, designed for dry skin; therapeutic for various skin diseases, rashes and acne; restoring the complexion (thanks to the bioflavonoid rutin, which strengthens capillaries and removes redness); anti-inflammatory and antibacterial (here comes into play the bioflavonoid quercetin, which fights skin infections); anti-aging with a high concentration of plant antioxidants. The presence of iron and vitamin B gives capers useful properties for hair: prevents hair loss; stimulates growth; makes hair beautiful and shiny. Capers are collected exclusively by hand. This process is long and tedious, which is probably why they are quite expensive. But this did not prevent them from taking a worthy place in the cuisines of some countries in ancient times. Tiny sour-salty capers can make a wonderful side dish for pizza, chicken, fish or meat. Feel free to add them to salads, soups, stews and sauces [Eshankulova N. T.et.all, 2012, Eshonkulova N.,Merganov A. 2014]

Capers or Capparis, capers - are the unopened flower buds of capers (caper Bush). In diameter, thesebuds are about $1 \mathrm{~cm}$. Capers grow in southern Europe and North Africa. The original taste of capers and low-calorie content made this plant a popular product for humans more than 2000 years ago, and maybe even earlier. The Greeks started using capers for food. Presumably, capers owe their name to the Greek name of the island of Cyprus (Kypros).

The ratio of BZHU in the product: nutritional value-100 $\mathrm{g}$-calories 23 , calories from fat $7.74 \%$ Daily value* Total fat $0.86 \mathrm{~g} 1 \%$ Saturated. Fat $0.23 \mathrm{~g} 1 \%$ Polyunsaturated.fat $0.3 \mathrm{~g}$ Monounsaturated. fat $0.06 \mathrm{~g}$ Cholesterol $0 \mathrm{mg} \mathrm{0 \%}$ Sodium $2348 \mathrm{mg}$ 98\% Potassium $40 \mathrm{mg} \mathrm{1 \%}$, total carbohydrates $4.89 \mathrm{~g} 2 \%$, sugar $0.41 \mathrm{~g}$, dietary fiber $3.2 \mathrm{~g} 13 \%$, Protein $2.36 \mathrm{~g} \mathrm{5 \%}$

Vitamin A3\% Vitamin B61\% Vitamin C7\% Vitamin K31\% Niacin 3\% Thiamine 1\%

Iron 9\% Calcium 4\% Magnesium 8\% Phosphorus $1 \%$ Zinc $2 \%$ Calculation for a daily diet of 2000 kcal

Currently, capers are produced by Middle earth sea countries: Turkey, Greece, Spain, Cyprus and Islands belonging to Italy. It is in these places that caper bushes have been growing in the wild for many centuries. Other States, as well as in our Republic of Uzbekistan, are trying to cultivate this plant. So, in Armenia and Georgia bred relative of capers - jongol or jonjoli. [Trili N, Nasri N, Saadaoui E, et al. 2009]

Useful properties and caloric content of capers. The benefits of capers and their taste, original and refined, are appreciated by the traditional cuisine of the southern peoples, and this product, which appeared in our country not too long ago, quickly began to gain popularity. Along with the excellent taste, capers have invaluable health benefits. So, the main medicinal properties of capers are: analgesic, antiseptic, astringent,antiinflammatory, diuretic.

Capers seeds contain about $36 \%$ oil. There are a lot of vitamins in capers: Vitamin A; Vitamin B1; Vitamin B2; Vitamin B4; Vitamin B5; Vitamin B6; Vitamin C; Vitamin E; Vitamin K; Vitamin PP. In addition, the benefits of capers are represented by a wide list of trace elements included in their composition: $\mathrm{Na}, \mathrm{K}, \mathrm{Fe}, \mathrm{Mg}, \mathrm{Zn}, \mathrm{Cu}, \mathrm{Se}, \mathrm{P}, \mathrm{Mn}, \mathrm{Ca}$ in sufficient quantities. [Suleiman, M.K., Bhat, N.R., Abdal, M.S., Jacob, S., Thomas, R.R., AlDossery, S., V Bellen, R. 2009]/

Along with the high benefits of capers, their caloric content is very low, so you can eat them without worrying about your body. So, the caloric content of capers is only 23 kilocalories. However, such valuable indicators as the low caloric content of capers and the health benefits are slightly muted due to their too high sodium content. Excessive concentrations of this trace element can have a negative impact on human health. Therefore, to neutralize this harm, capers are soaked in water before use. But the benefits of capers will be very noticeable when they are soaked in olive oil. The caloric content of capers preserved in oil remains almost at the same level, changing slightly, and therefore even in this case they remain a dietary product. The nutritional value of canned capers is: protein $-2-3 \%$; Fat $-0.9 \%$; carbohydrates $-1.7 \%$.

The use of capers: Since ancient times, this plant has been used for healing wounds, against toothaches, heart pains and headaches. To do this, they were prepared decoctions from all parts of the caper (flowers, fruits, roots, leaves). The benefits of capers lie in a powerful antiinflammatory and analgesic effect, which is used to fight various diseases. So, regular use of capers in food helps to cope with rheumatic pain.

They are also recommended for other health problems: flatulence, thyroid diseases, dentistry (diseases of the teeth and gums), and cardiovascular diseases. Traditional medicine uses the benefits of capers for a long time and very actively. So, all parts of this plant are used by healers to fight such ailments as: hypertension; 
scabies; jaundice; neurosis; brucellosis. All sorts of manifestations of allergies and rheumatism were cured by the ancient Arabs with the help of caper root. Unopened capers buds are also an excellent stimulant for stimulating the appetite. Currently, the pharmaceutical industry also uses the significant benefits of capers in the manufacturing of medicines[Inocencio C, Alcaraz F, Calderon F, et al. 2002, Kan , Y., \&Arslan, N. 2002. Eshankulova N.T., 2015]. So, capers are used in the production of drugs of the following pharmacological groups: sedative, diuretic, antiseptic, choleretic.

In cooking, use unopened buds, as well as young shoots of this plant. In fact, caper, in our understanding, is marinated in vinegar, with the addition of salt, unopened caper flower, although ripe caper fruits can also be used for food, and in fresh form. Collecting the buds of capers is a simple process, but the main thing is to process them correctly: either salt or marinate them.

Incomparable to anything, the intense taste of capers is formed due to the mustard oils that come out of them during the marinating process in vinegar. On the surface of capers, under the influence of marinade, white spots are formed this is nothing more than a crystallized rutin (actually, vitamin PP)[Rhizopoulou S, Ioannidi E, Alexandredes N, et al. 2006]

Ripe capers can be eaten raw, but they are usually marinated. Capers are a mandatory and important element of the cuisine of various countries and peoples. The bright, sharp-salty taste of capers adorns a variety of salads, pizza, sauces, meat and fish dishes. The low caloric content of capers and their taste find their use in making of one of the most popular sauces - Tartar sauce. The taste of capers and olives is perfectly combined. In addition, in Greek cuisine, for example, not only flowers and fruits are used for food, but also capers leaves. They are also boiled or marinated, and then included in salads and fish dishes. Dried capers leaves are used in the manufacture of hard cheeses, for sourdough, instead of rennet. [Inocencio C, Alcaraz F, Calderon F, et al. 2002. EshonkulovaN.,Merganov A., 2014]

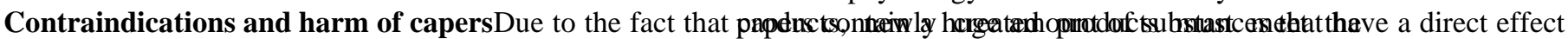
increased sexual excitability. Absolute contraindications to the use of capers are pregnancy - due to high sodium content, and individual intolerance to this product, in this case it causes allergies. [Higton, R. N. \&Akeroyd, G. R. 1991]

Studies of the wild form of this plant have shown that Capparisspinosa.L. is a perennial herb which is multi-year, woody at the base, glabrous or scattered hairy shoots $200-370 \mathrm{~cm}$ long. The young parts of the plant are more or less densely covered with subsequently falling hairs [Eshankulova $\mathrm{N}$. T.,et,al. 2012]. It should be noted that this genus included about 300 species of shrubs, trees, lianas and perennial grasses, common not only in arid, but also in subtropical and tropical regions of the planet. Currently, the number of genera has increased to 45, and the number of species to 900 . [Eshankulova N.T., 2013]

Stipules in the form of yellow slightly curved spines are $4-7 \mathrm{~mm}$ long. Flowers are large, from $4-5$ to $8 \mathrm{~cm}$, fragrant, single in the leaf axils, sepals (4 PCs) concave, ovate pointed outside, short depressed, green. Pedicels are usually longer than the adjacent leaf $(3-5 \mathrm{~cm})$. The fruits are green, with a smooth surface and longitudinal white veins, sit on long legs - gynophores and vary greatly in shape and size, $3-6 \mathrm{~cm}$ long, $1.5-3 \mathrm{~cm}$ wide. The fruit contains up to 570 seeds located in its crimson-red pulp. Fruits ripen in June-October. In Spain, Italy, France and Africa, varietal capers are grown. On the Italian island of Pantelleria, capers are grown with the IGP brand(protected geographical name) [Eshankulova N.T., 2013]. The best varieties of capers compete with grapes in terms of profitability, especially since the cost of growing capers is minimal, and about $3 \mathrm{~kg}$ of buds are collected from one plant per season.

Like all plants, capers are rich in vitamins, fiber, and organic acids. The buds contain about $25 \%$ protein and $3 \%$ fat, the fruits being rich in vitamin $\mathrm{C}$ and iodine, and with the seeds containing up to $36 \%$ oil.

Evaluation of the quality of products currently sold has shown the need to develop a method for improving the quality of raw materials and optimizing the ingredient composition in order to improve the consumer properties of the medicinal product.

All its prescription ingredients have a significant impact on the quality indicators of capers, but the quality of raw materials used in pharmaceuticals is of particular importance and relevance at the present time. The quality of plant products is determined by a set of characteristics, primarily food and medicinal value, combining biological value, organoleptic and sanitaryhygienic, microbiological and safety indicators.

In accordance with the current provisions of the physiology and biochemistry of food medical and biological requirements for functional food products.

According to the concept of a balanced diet, for normal human life, it is necessary not only to get the necessary nutrients into the body, but also to ensure certain quantitative ratios between them.

In the composition of fruits of vegetable raw materials - capers can be such substances that give the product dietary and medicinal properties.

In this regard, we have studied the indicators of nutritional and curative value of capers, i.e. the analysis of plant raw materials in 
order to obtain a protein-vitamin complex (protein, polysaccharides, flavonoids, pectin) from caper fruits and allows us to enrich the composition with easily digestible protein balanced by essential amino acids, vitamins, flavonoids, micro-and macronutrients. The presence of polysaccharides (cellulose, pectin) contributes to the decorporation of heavy metals, due to the presence of free carboxyl groups (-COOH) and $\mathrm{OH}$ - (hydroxyl groups that form stable low - dissociating compounds with metal ions-chelates, the occurrence of which prevents the entry of heavy metals into the internal environment of the body. Flavonoid compounds of this plant possess antioxidant activity, catalyzing the oxidation processes. Table 1 shows a preliminary analysis of the initial composition of the feather grass homogenate obtained by physical crushing in a homogenizer.

Our research and literature data have shown that capers contain rutin at a concentration of $0.32-0.35 \%, 130-150 \mathrm{mg} \%$ vitamins C, P, E, etc., $12 \%$ carbohydrates, $1820 \%$ flavonoids, 29 $30 \%$ glycosides, $35-36 \%$ fat in seeds, $25 \%$ protein in buds, and 27-30 mg iodine in capers.

To isolate the enzymes of the cellulase complex, 10-day culture liquid Aspergillus terreusH9 was first filtered through glass wool, then through a Millipore filter (pore size 0.2 microns) to separate from the culture cells.

To process capers, enzymes of the fungus Pleurotusostreatus(Jacq.Ex. Fr.).Kumm.UzBI ZAX105/7 were used.Cultivation was carried out in depth at a temperature of $28-29^{\circ} \mathrm{C}$ in Erlenmeyer conical flasks with a volume of $750 \mathrm{ml}$ with $200 \mathrm{ml}$ of nutrient medium (pH-6.5) containing 1-3\% cotton pulp and 3\% wort, for 3-30 days on rocking chairs with a rotation speed of $250 \mathrm{rpm}$. Samplesweretakenafter 24 hours.

The amount of biomass was determined by weight method. To do this, the mycelium separated from the QL was washed 5-6 times with distilled water until clear water was obtained, dried, and the biomass yield was extractedfrom $100 \mathrm{ml}$ of the culture medium.

Phenol oxidases were isolated from the cells of Pleurotusostreatus, for which the fungus was grown on a medium containing depleted cotton seed meal, introduced into the nutrient medium as the only source of carbon. The mushroom with agar wort was sown in a presterilized culture medium containing 3\% wort and $3 \%$ cotton pulp. Laccase activity was determined in QL spectrophotometrically by the rate of accumulation of pyrocatechin oxidation products at $410 \mathrm{~nm}(\mathrm{E} 410=740 \mathrm{M} \mathrm{cm})$. The reaction mixture consisted of $2 \mathrm{ml}$ of $0.1 \mathrm{M}$ acetate buffer $\mathrm{pH}-4.5 ; 0.5 \mathrm{ml}$ of $0.1 \mathrm{M}$ pyrocatechin and $100 \mathrm{ml}$ of enzyme protein. The amount of the enzyme that catalyzes the formation of $1 \mathrm{mmol}$ of pyrocatechin oxidation products per unit of time was taken as a unit of activity [Eshankulova N.T., Akhmedova Z.R., 2013]

Peroxidase (K. F. 1.11.1.7 donor: $\mathrm{H}_{2} \mathrm{O}_{2}$ oxidoreductase ) was determined by the oxidation of o-dianisidine. The composition of the reaction mixture: $100 \mathrm{mcl}$ of $0.2 \%$ o-dianisidine solution in a phosphate buffer, $\mathrm{pH}-5.9,20 \mu \mathrm{l}$ of $0.05 \%$ hydrogen peroxide solution, $100 \mu \mathrm{m}$ of the enzyme. The mixture was incubated for 10 minutes at room temperature, and after the incubation period, the reaction was stopped by adding $2.5 \mathrm{ml}$ of $50 \%$ $\mathrm{H}_{2} \mathrm{SO}_{4}$. The unit of peroxidase activity corresponded to the amount of the enzyme that catalyzes the conversion of $1 \mathrm{MK} /$ molof $\mathrm{H}_{2} \mathrm{O}_{2}$ in 1 min.under optimal conditions. The activity of polyphenol oxidase was determined by the oxidation of guaiacol[Pruntova O.V.,Sakhno O. N]. The method is based on spectrophotometric measurement of the guaiacol oxidation rate at 410 $\mathrm{nm}(\mathrm{E} 410=710 \mathrm{M}-1 \mathrm{~cm}-1)$. The reaction mixture consisted of $0.1 \mathrm{M}$ acetate buffer, $\mathrm{pH} 4.5$, and 0.1 $M$ substrate. As a unit of activity, the amount of enzyme required for the formation of 1 micron of substrate oxidation products in $1 \mathrm{~min}$.per $1 \mathrm{mg}$ of enzyme protein was taken.

The following existing methods were used in biochemical studies of the composition of capers fruit elements.Determination of protein by formal titration using the I-160 ionomer and the automatic titration unit BAT-15.2, as well as by the Lowry method, as well as by Keldahl[Zvyagintsev D. G., 1991, Journal of analytical chemistry, 1951].IR spectra of pulp and seeds using the Fourier method. The carbohydrate content was determined using the refractometric method and the Dubois method [Zvyagintsev D. G., 1991]. The vitamin content was determined by infrared spectroscopy on an IR-4500 device and by high-performance liquid chromatography on a milichrom chromatograph. Water-soluble vitamins were determined using the method developed by I. E. Mitin and N. A. Golubkina.

Phenolic substances were isolated using various concentrations of ethanol and glycerol and in their combinations. The content was determined by Gallic acid titrimetric method. Qualitative assessment of the protease was performed using $10 \%$ gelatin in an agarized medium at $\mathrm{pH} 2.5,5.5$, and 6.2. the $\mathrm{pH}$ of the raw material was determined by a potentiometric method using the $\mathrm{PH}$ meter "LPU-340".

Determination of the mineral content by the accelerated method using magnesium acetate, the ash content was determined by the accelerated method, adding a solution of magnesium acetic acid. The air and absolutely dry weight of the samples was determined in a drying Cabinet at 
200C for 30 minutes, and in a muffle furnace at 550C, also for 30 minutes[Eshonkulova N., 2013].

The mass concentration of calcium, potassium, phosphorus, and zinc was determined by atomic absorption spectrometry using a calibration graph of the concentration of elements in solution, $\mathrm{mcg} / \mathrm{ml}$. Determination of bacteriostatic and bactericidal activity of extracts of capers fruit elements was carried out by nephelometric method using pure culture of E. coli and S. aureus, each separately sown on MPA and grown in a thermostat at a temperature of $370 \mathrm{C}$ for 24 hours. Then it was washed off with a sterile isotonic solution of sodium chloride and standardized to a content of 1 $\mathrm{ml} 2$ billion microbe cell. This suspension was seeded for $\mathrm{BCH}$ in test tubes and grown in a thermostat at $370 \mathrm{C}$ for 24 hours. To determine the bactericidal activity, a nutrient medium (Hottinger broth enriched with peptone) containing $200 \mathrm{mg} \%$ of amine nitrogen was used [Eshonkulova N., 2013]

The Wartburg spectrophotometric method was used to determine aromatic substances and amino acids that absorb light with a wavelength of 245$445 \mathrm{~nm}$. The fat content was determined by the sox let method, based on the extraction of fat from a dried sample with volatile solvents according to GOST 23042-86, and the determination of sodium chloride was carried out according to GOST 995773 [Zvyagintsev D. G., 1991].

The study of the chemical composition in the comparative aspect of capers collected from wild forms and cultivated forms, i.e. growing in natural natural umloviya and bred by seed sowing showed that the concentration of almost all chemical components is high in the cultivated form of capers. biologically valuable substances (Table.1)

Table.1: Comparative content of chemical substances in the fruits of capers (region Namangan, \%)

\begin{tabular}{|l|l|c|cc|}
\hline Substances & $\begin{array}{c}\text { Theaverage } \\
\text { quantities }\end{array}$ & $\begin{array}{c}\text { Wild } \\
\text { form of the }\end{array}$ & \multicolumn{2}{|c|}{$\begin{array}{c}\text { Cultivated form of } \\
\text { the plant }\end{array}$} \\
\hline Ruthin & 032 & 029 & 035 & $(200 \%)$ \\
\hline ascorbicacid & 150 & 147 & 154 & $(4.8 \%)$ \\
\hline Vitamin PP & 136 & 131 & 140 & $(69 \%)$ \\
\hline Vitamin E & 128 & 126 & 130 & $(3,2 \%)$ \\
\hline Quercetin & 043 & 039 & 0,48 & $(23,1 \%)$ \\
\hline Sugar & 8,12 & 8,0 & 12,0 & $(50 \%)$. \\
\hline Glycosides & $21-29$ & 21,0 & 29,0 & $(38 \%)$ \\
\hline Thelipidsofsee & 36 & 34,0 & 37,0 & $(8,8$ \\
\hline Proteins & 25 & 24,0 & 26,0 & $(8,3 \%)$ \\
\hline $\begin{array}{l}\text { Iodine (mg per } \\
\text { 100 grams of dry } \\
\text { weight) }\end{array}$ & 27 мГ & 24,0 & & \\
\end{tabular}

The distinctively high content of carbohydrates-50\%, 20\% flavonoids, 29-30\% glycosides and almost $38 \%$, then quercetin by 23.1 $\%$, then iodine $20.8 \%$ and routine by $20 \%$ shows that the fruits of cultivated capers are quite suitable for food preparation and preventive action, in particular for the treatment of anemia, iodine deficiency, infectious and hematological patients, and most importantly they can be used for cooking various food products. (2-Table)

Capers also contain up to $136 \mathrm{mg} \%$ ascorbic acid, glycosides, steroid saponins, the enzyme myrosin, and red pigment,

Table 2: Biochemical composition of caper fruits (Namangan region, \%)

\begin{tabular}{|l|l|l|l|}
\hline Indicators & $\begin{array}{l}\text { Wildformsofpl } \\
\text { ants }\end{array}$ & $\begin{array}{l}\text { Cultivatedforms } \\
\text { of plants }\end{array}$ & $\begin{array}{l}\text { Improvingperforman } \\
\text { ce }\end{array}$ \\
\hline The moisture content of the fruit, \% & $65-70$ & $68-73$ & 3,0 \\
\hline Air-dryweight, g . & $23-26$ & $28-31$ & $5-6$ \\
\hline Ashsubstances, \% & $4,0-4,2$ & $3,8-4,2$ & 0,2 \\
\hline InitialpH (fruitextract) & $3,9-4,1$ & $3,5-3,8$ & a decline of0,4-0,3 \\
\hline Rawfiber, in \% & $10-12$ & $7,0-10$ & a declineofa 3-2 \\
\hline Rutin, mg/100 g & 0,29 & 0,35 & 0,6 \\
\hline Vitamin C.mg. \% & 147 & 154 & 7 \\
\hline Totalcarbohydrates. \% & 8.0 & 12.0 & 4 \\
\hline broteins. \% & 14.0 & 19 & 5 \\
\hline
\end{tabular}




\begin{tabular}{|l|l|l|l|}
\hline Iodine (mg/100 grams) s. v.) & 17,4 & 29,0 & 11,6 \\
\hline Extractives, \% & 6,5 & 5,7 & a declineof0,8 \\
\hline Organicacid, \% & 12 & 13,8 & 1,8 \\
\hline
\end{tabular}

Caper proteins contain the amino acids threonine, leucine, alanine, aspartic acid, phenylalanine, glycine, lysine, arginine, asparagine, methionine, Proline, tryptophan, glutamine, and histidine.
Analysis of the chemical composition of capers shows the valuable composition of this plant (Table-3).

Table 3. General chemical composition of caper fruit

\begin{tabular}{|l|l|}
\hline Chemical composition of caper fruit & $\begin{array}{l}\text { Quantity } \\
\text { in } 100 \mathrm{~g}\end{array}$ \\
\hline Protein, in \% & $14-16$ \\
\hline Fiberin \% & $7,0-10$ \\
\hline Fats from the seeds of the wild type, in \% (control) & $23-26$ \\
\hline Fats from seeds of the cultivated form, in \% (experience) & $33-36$ \\
\hline Carbohydrates, in \% & $15-27$ \\
\hline
\end{tabular}

As can be seen from table 1 , in capers homogenate, the protein content was $14-16 \%$ in capers pulp, and $7-10 \%$ in raw fiber. The amount of total fat contained in the seeds of the wild form of

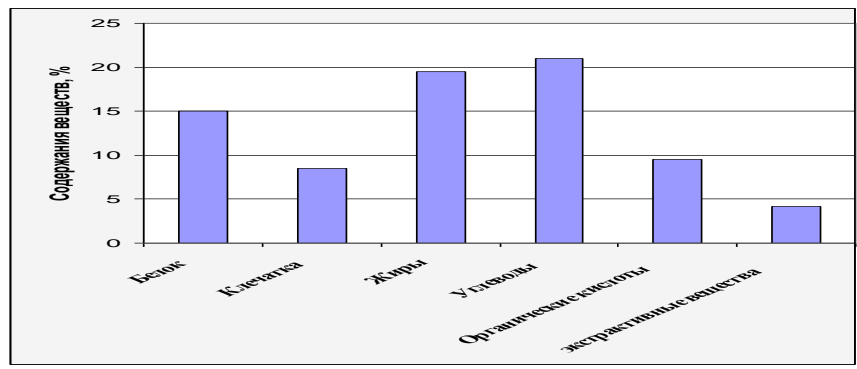

A

Figure-1.The share composition of the main biotechnologically valuable substances of fruits in wild (A) and grown by the enzymobiotechnological method capers $(B)$.

The figure shows that the content of organic acids $(22 \%)$, extractive substances $(9.0 \%)$ is higher in the wild form than in the cultivated form $(12 \%)$ of the plant, the remaining substances, i.e. carbohydrates, proteins, fats, and clots, were high compared to the control variants.

The selection of raw materials and the selection of the component composition of food production was carried out exclusively from natural raw materials, which are biologically valuable, highly effective adaptogens, immunomodulators, and biocorrectors.

So to establish this fact, there must be a basis for determining the content in them in the capers extracted by chloroform on the Soxlet apparatus was $18-21 \%$, the cultivated form-33-36 $\%$. the total amount of carbohydrates determined by the Dubois method was 15-27\% (figure.1).

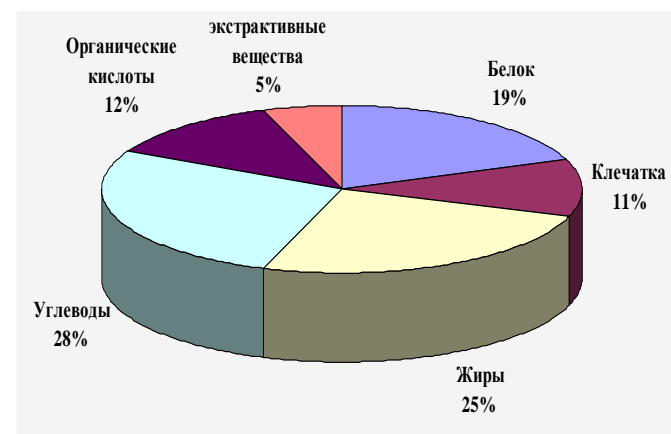

B

optimal ratio of all the elements necessary for the body (carbohydrates, proteins, fats, vitamins, etc.), enriched with essential and interchangeable amino acids, vitamins (B2, B6, C and D), complete and easily digestible mineral elements (calcium, phosphorus, magnesium, potassium, iron, etc.).

Of considerable interest is the study of the vitamin composition of capers, since they were found to contain a large concentration of biologically valuable substances. An initial study of the composition and number of water-soluble vitamins showed that ascorbic acid makes up the majority, i.e., from $40 \mathrm{mg}$ to $56 \mathrm{mg} / \mathrm{g}$ per dry weight of unripe capers fruits (Table-4). 
Table-4: Vitamin composition of fruits of capers

\begin{tabular}{|l|l|}
\hline Substances & Content, $\mathbf{~ m g / 1 0 0 ~ g}$ \\
\hline Organicacid & $7,6-11,5$ \\
\hline B-2 Vitamins & $0,9-1,7$ \\
\hline B-6Vitamins & $1,3-2,1$ \\
\hline C- Vitamins & $40-56$ \\
\hline
\end{tabular}

In the literature, there is information that the fruits of capers lower blood pressure, reduce flatulence, has an anti-rheumatic effect, a decoction of capers flowers heals wounds, strengthens the heart, while a decoction made from the roots has an analgesic effect, a decoction of bark treats neurosis. So, the astringent, antiseptic, analgesic, and other properties of this plant make it very valuable both for the pharmaceutical and medical, and in the food industry. In addition, the juice obtained from the fruit cures paralysis, the root bark of its own experiments have shown that
Capparisspinosa L., the same Kovyl, the same capers, namely the Central Asian genus and species of Capparisellipsoids, may well serve as sources of biologically valuable and physiologically active substances, which areimportant both in medicine and pharmaceutical (folk and traditional), and in food production.

Studies of the mineral composition of capers have shown that they contain a high concentration of macronutrients, such as potassium, phosphorus, sodium, etc. (Table-5)

\begin{tabular}{|l|l|}
\multicolumn{1}{c}{ Table5: The total content of macro elements in fruits of caper } \\
\hline Macroelements & Quantities \\
\hline Calcium, $\mathrm{mg} / \mathrm{l00g}$ & $115-220$ \\
\hline Phosphorus, $\mathrm{mg} / 100 \mathrm{~g}$ & $125-220$ \\
\hline Potassium, $\mathrm{mg} / 100 \mathrm{~g}$ & $250-500$ \\
\hline Sodium, $\mathrm{mg} / 100 \mathrm{~g}$ & $200-220$ \\
\hline Magnesium, $\mathrm{mg} / 100 \mathrm{~g}$ & $25-30$ \\
\hline
\end{tabular}

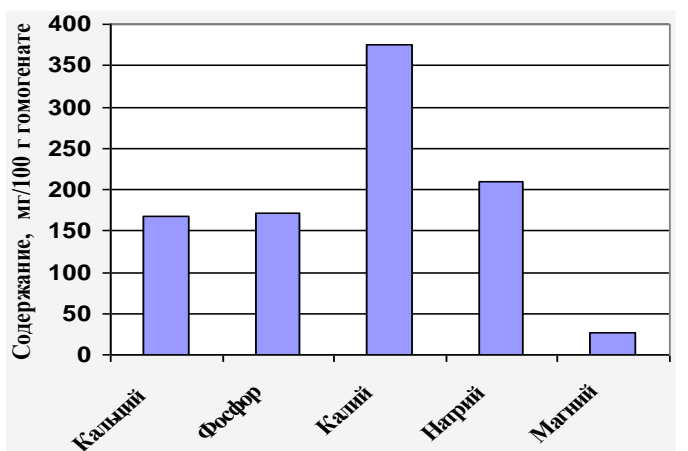

A

Figure-2.Diagram of the content of compound macronutrients in caper fruits wild (A) and grown by capers enzyme technology $(B)$

The study of the content of macronutrients in the wild capers fruit showed that it contains a large amount of potassium salt $(370 \mathrm{mg} / 100 \mathrm{~g})$, then sodium $(220 \mathrm{mg} / 100 \mathrm{~g}$, then phosphorus $(175$ $\mathrm{mg} / 100 \mathrm{~g})$, calcium (268 $\mathrm{mg} / 100 \mathrm{~g})$, and magnesium salts are the lowest concentration -25 $30 \mathrm{mg} / \mathrm{g}$.

The search for economically feasible ways to improve the biotechnological properties of yeast in bakery production has shown the prospects of pre-treatment of yeast cells in a nutrient mixture using natural sugar-containing additives that have a

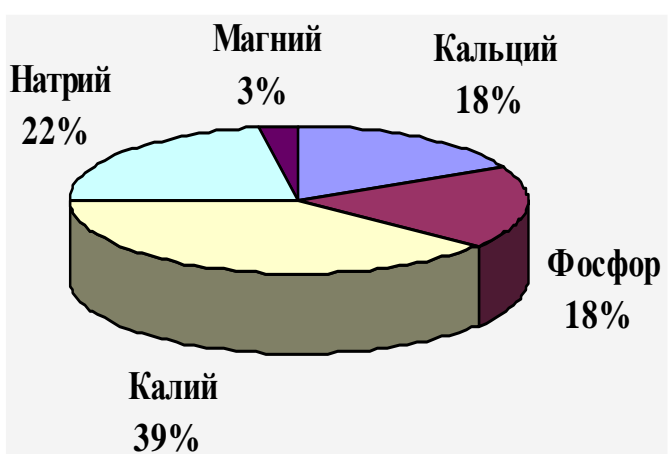

B

number of nutritional and healing properties [Ermakov A. I., Arasimovich V. A., 1972].

In this regard, natural vegetable raw materials are of interest, in particular products of fruit and vegetable processing, characterized by the presence of sugars, minerals, organic acids, vitamins and other biologically active nutrients necessary for the enrichment of semi-finished products.

Studies have shown that yeast plays a special role not only in relation to its extensive distribution in nature, but also due to its fermentation capacity, which depends on the 
preparation of a wide variety of food products. Features of the structure and functioning activity of yeast cells are very complex, manifested not only in media containing free sugars, but also a variety of polysaccharides (starch, inulin, pectin, etc.). The macromolecule of yeast, the structure of cellular organelles and their energy, as well as active exchange with the nutrient medium, high enzymatic activity, and a relatively short cycle of their development make it possible to control a variety of processes of their metabolism, which also makes them promising for evaluating the biological value (OBC) of food additives of various origins, as well as in determining their suitability and digestibility, not pathogenicity.

Bread production is associated with various technologies due to historical and national characteristics. It is based on the processes of dough preparation and baking. Modern methods of dough preparation include both traditional and nontraditional processes, i.e. the use of various additives, not only technological, but also enriching their composition, improving their quality.

Today, it is very important and in demand to use additives in the dough in the form of dried vegetables, fruits, syrups, sweeteners, dietary fiber and other biological additives that complement the composition of bread with the most important essential nutrients: ascorbic acid, beta-carotenes, bioflavonoids and dietary fiber. This bread is not only good for health, but also delicious, it also has therapeutic and preventive properties.

The quality of bread directly depends on the components of the recipe, as well as the implementation of technological regulations and storage conditions. The addition of fruit and vegetable additives can lead to changes in humidity, increase or decrease in acidity, as well as porosity of bread, which can lead not only to a deterioration in the organoleptic characteristics of bread, but also its digestibility and the degree of digestibility of nutrients and bread.

Bread, as a rule, should not be a medium for the development of microorganisms that can cause food poisoning. However, the introduction of fruit and vegetable additives in its composition may contribute to microbiological spoilage of bread.

Therefore, the purpose of our research was a preliminary assessment of biological fruit and vegetable additives intended for adding bread, namely, conducting a Toxicological assessment of bread prepared with various dried vegetable additives. Intragastric administration of bread extract samples to laboratory animals was performed, followed by the study of its effect on the main biochemical parameters of internal organs, which is the first and mandatory stage of medical and biological evaluation of new food products.
This observation will provide information for the assessment and classification of products and their belonging to the categories of safety and toxic risk.

\section{Trade name and characteristics:}

1.1. Name - bread with dried additives in the following assortment: bread with the addition of ground powder of dried fruits and buds, capers flowers

1.2. Organoleptic characteristics: shape regular bread, without the side viplavam; surface smooth, without cracks and gaps; the color corresponds additives products from capers- pale yellow); crumb baked, not moist, without a trace of nephromas, porosity is moderate, small, taste and smell corresponds to the prescription fillers, flexible, organized-compact. .

1.3. Physical and chemical indicators: humidity of bread - with dried fruit capers $44.0 \%$, with flowers $-45.0 \%$; acidity - with dried fruit $-3.0 \mathrm{deg}$, flowers $-3.5 \mathrm{deg}$, buds $-4.0 \mathrm{deg}$;

1.4. Application: as a ready-to-eat food product with high nutritional value.

\section{Storage}

Laboratory of food hygiene research Institute SGPS MOH of the Republic of Uzbekistan maintains the plan of study, current data samples of the object of study and the final report of this test for ten years, after which all data can be destroyed without the consent of the Customer.

\subsection{Compliance statement}

Studies of the toxicity of the studied samples of bread with dried capers additives in the studied assortment were conducted in accordance with qualitative and laboratory practical standards:

Regulations of laboratory practice from 2.02.2000 (R. S. 813.016.5). This provision is based on the OECD principles of quality of laboratory practice, revised and adopted on 26.11.1997 by the decision of the OECD Council.

During the research, no extraordinary circumstances were observed that could affect the quality and reliability of the results obtained.

\subsection{Certification}

Equipment NAGPS $\mathrm{MOH}$ of $\mathrm{RUz}$ for research certified by the State Committee of standardization and Metrology of the Republic of Uzbekistan for № 38 dated 15.06.09, the license for the right of rendering of medical services, Ministry of health of the Republic of Uzbekistan No. 4606 dated 17.06.05 g

The obtained research results, reflected in the conclusion, relate to the objects of research and information of the measurement error test, information about which is provided only within the limits of the request and cannot be reproduced without the written permission of the research customer. 
The use of fruit and vegetable feeders in the preparation of biotechnological dietary food products and evaluation of finished products.

In accordance with the above, we conducted research on the development of a promising technology for activating baking yeast using powdered vegetable substrates, from flowers and buds of capers for accelerated methods of preparing dough from wheat flour, with their further baking to increase the bread assortment.

As objects of research, we used Baker's yeast Saccharomyces cerevisiae, strain 2, previously used by us for the preparation of fermented yeast based on Jerusalem artichoke tubers, crushed Bud with inflorescence (BC) that meets the requirements of TS 64. 1831008901:2002, andwheatflourofthe 1st grade "Uzbekistan".

It was found that the dry substances of the studied substrate are mainly represented by

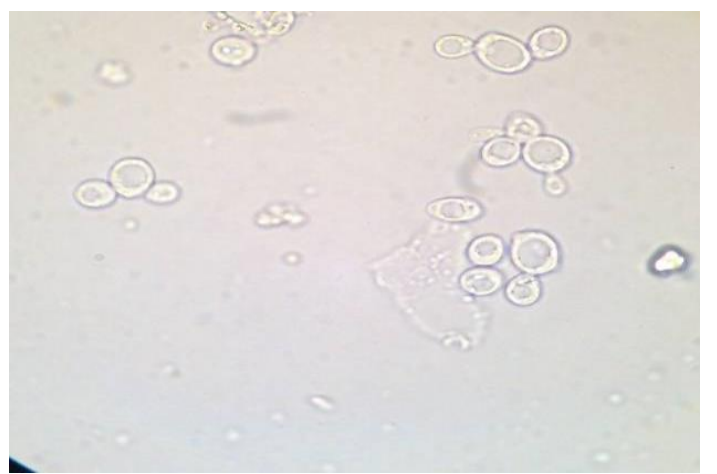

Figure-3 A1 - option: Yeast growth on a medium with wort+ $\mathrm{NaCl}(0.036 \mathrm{~g})+$ dist. water $(19.76 \mathrm{ml})$ (dilution $\mathrm{x}$ 1:1000 times)

Figure- 3.Microscopic view of yeast grown for 6 hours on media with wort and caper Bud powder

Thus, the cultivation of baking yeast was carried out according to the method given in the manual [Polandova, R. D., 1984]. It was found that crushed concrete samples with capers flowers activate yeast growth 3-times more than the control medium, which dictates the need to use this substrate to accelerate the maturation of flour semifinished products.

The recommended culture medium formulation for activating Baker's yeast is as follows:

Control (0.33 g wheat flour grade $1+$ $0.086 \mathrm{~g} \mathrm{NaCl}+19.66 \mathrm{~cm} 3$ distilled water);

Experience: BCC was added in the amount of $1.0 \%$, the rest was also controlled.

The prepared samples were autoclaved for 60 minutes at a pressure of 1 ATM. After holding the mixture for 24 hours, the test samples were inoculated with yeast suspension (Saccharomyces) by washing the jamb with distilled water in an amount of $12 \mathrm{~cm} 3$, then this wash was introduced into test tubes with nutrient media of $1 \mathrm{~cm} 3$, which carbohydrates: glucose, fructose, mineral elements, as well as iodine and aromatic ether-like substances, a small amount of cellulose is contained. Of the sugars, glucose and fructose predominate, easily fermented by yeast. The elemental and vitamin composition is very diverse [Matveeva, I. G. Belyavskaya., 2001].

For a preliminary assessment of the suitability of $\mathrm{BC}$, sterile nutrient media containing $\mathrm{BC}$ and wort (control) were prepared with the addition of distilled water and table salt, yeast was seeded and the growth and development of yeast was observed on these media for 3-6 hours (Fig.3 A, B).

The study of the growth and development of yeast on sterilized nutrient media containing the initial semi-finished products showed that rapid growth of yeast was observed on the medium with pumpkin powder, then with carrot and beet powder, then with red pepper powder and Bordeaux beet.

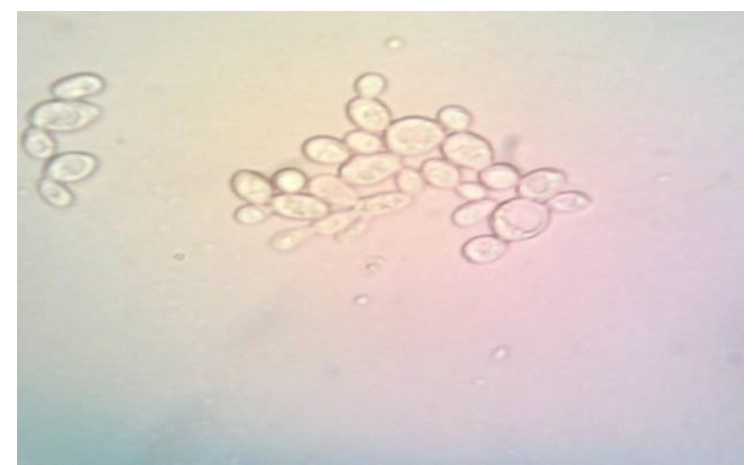

Figure-3 B 2-option: yeast growth on medium with crushed flowers and Caprice Bud $(0.2 \mathrm{~g})+\mathrm{NaCl}$ $(0.036 \mathrm{~g})+$ dist. water $(19.76 \mathrm{ml})$ (dilution $\times$ 1:1000

were then thermostated at a temperature of $27^{\circ} \mathrm{C}$ for 3 hours.

During this period, an increase in yeast biomass was observed by visual observation and by counting the number of cells in the Goryaevchamber. To do this, a $0.01 \mathrm{ml}$ yeast suspension was used, with which the chamber was filled using a Pasteur pipette, and after a few minutes, when the yeast settled to the bottom of the chamber, the counting was started with an $8 \mathrm{X}$ or $40 \mathrm{x}$ lens. To obtain reliable results, the calculation was performed in three preparations in 5 large (area $1 / 25 \mathrm{~mm} 2$ ) or 20 small (area $1 / 400 \mathrm{~mm} 2$ ) squares. Then we found the average number of yeast cells in one square, i.e. in fact, the volume is $1 / 250 \mathrm{~mm} 2$ $(1 / 25 \mathrm{~mm} 2 \times 1 / 10 \mathrm{~mm})$ or $1 / 4000 \mathrm{~mm} 2(1 / 400 \mathrm{~mm} 2$ $\mathrm{X} 1 / 10 \mathrm{~mm}$ ). When multiplying the found average number by the denominator of the fraction (250 and 4000 ), the number of yeast cells in $1 \mathrm{~mm} 3$ was found, multiplied by 1000 , in $1 \mathrm{~cm} 3$ (ml) of the suspension. 
Further, the number of yeast cells in 1 mo of the yeast suspension was determined by the formula [6.2]: $X=\underline{a} \underline{a} b, \mathrm{~B}$

where a - number of yeast cells in $1 \mathrm{ml}$ of suspension;

$\mathrm{b}$ - the volume of the prepared suspension, $\mathrm{ml}$;

B - total volume of activated yeast (in $\mathrm{ml}$ ).

Usually, the I $\mathrm{g}$ of good-quality compressed yeast contains from 8 to 12 billion. viable cells. Since direct counting does not make it possible to distinguish living cells from dead ones, the number of the latter is determined by an additional study. To do this, a drop of yeast suspension was placed on a slide, added to it at the tip of a match of methylene blue (the color of the drop should be blue, not blue), covered with a cover glass and after 1-2 minutes microscopized with a 40x lens. We calculated the number of colored and unpainted cells in 10 fields of view, finding the arithmetic mean percentage of dead cells and reducing the amount of yeast cells in I $g$ by this number.

Also, the intensity of the gas formation process in the studied nutrient mixtures and changes in the mass fraction of protein in them were analyzed using the Lowry method. (The results are presented in Table. 6 and Table 7 and shown in figure. 3,4$)$.

Table6.Influence of the substrate on the dynamics of yeast biomass accumulation

\begin{tabular}{|l|l|l|l|l|l|}
\hline \multirow{2}{*}{$\begin{array}{l}\text { Options } \\
\text { experience }\end{array}$} & \multicolumn{2}{|l|}{ Quantity of yeast cells, $10 \mathrm{sm}^{3}$} & \multicolumn{2}{l|}{ Growthofyeastcells } \\
\cline { 2 - 6 } & 12 hours & 16 hours & 20 hours & $\Delta, \%$ & $\begin{array}{l}\text { relative to tre } \\
\text { control, } \pm \Delta, \%\end{array}$ \\
\hline $\begin{array}{l}\text { Control } \\
\text { (molasses) }\end{array}$ & $2,89 \pm 0,2$ & $3,48 \pm 0,3$ & $3,75 \pm 0,2$ & 29,0 & - \\
\hline $\begin{array}{l}\text { Flower and } \\
\text { concrete capers } \\
(\text { FCC })\end{array}$ & $3,04 \pm 0,2$ & $3,89 \pm 0,4$ & $4,62 \pm 0,3$ & 51,9 & 22,9 \\
\hline
\end{tabular}

The method of pre-activation of yeast can reduce the prescription amount of yeast by $0.2 \%$ and flour by $2.0 \%$ in the production of wheat bread varieties (Table.6).

Table 7. Effect of activated yeast on the quality of dough and bread

\begin{tabular}{|l|l|l|}
\hline Nameofindicators & Control & FCC \\
\hline Dough:Humidity, \% & $4,0 \pm 0,3$ & $44,1 \pm 0,3$ \\
\hline Acidity, deg & $3,4 \pm 0,2$ & $4,2 \pm 0,1$ \\
\hline $\mathrm{pH}$ & 4,91 & 4,80 \\
\hline Liftingforce, min. & 28 & 24 \\
\hline Gas formation rate, $\mathrm{cm}^{3} \mathrm{CO}^{2} /$ hour. & 570 & 570 \\
\hline Bakedbread: Humidity, \% & $3,0 \pm 0,5$ & $43,1 \pm 0,3$ \\
\hline Acidity, deg & $2,2 \pm 0,2$ & $2,8 \pm 0,1$ \\
\hline Porosity, \% & 70,0 & 73,0 \\
\hline Volume output of bread, cm3 /100 g of flour & 478 & 482 \\
\hline Specific volume, cm3/100 g of bread & 338 & 345 \\
\hline Organolepticevaluation, thescore & 80 & 82 \\
\hline
\end{tabular}

The volume and yield of bread increased by $0.8-4.8 \%$, the specific volume by $2.1-4.7 \%$, and the porosity by $4.3-8.6 \%$ in the experimental samples with the addition of CBC. The effectiveness of the use of additives for baking

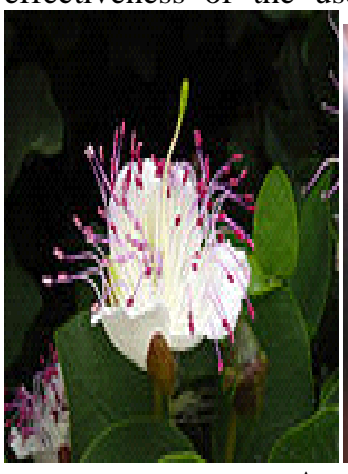

A

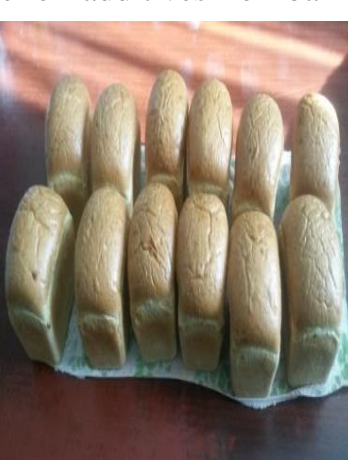

B

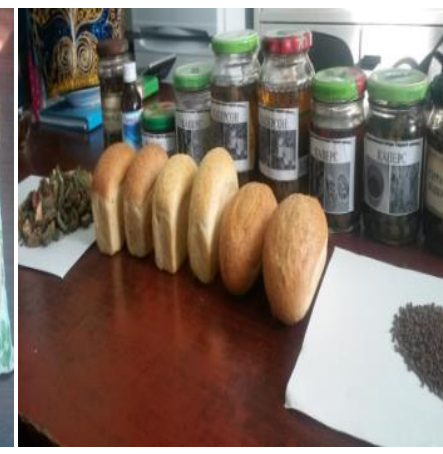

$\mathrm{C}$ bread is established, which will reduce the prescription amount of flour and yeast, reduce the duration of maturation of the dough by $35-40$ minutes and layering of dough pieces by $10-15$ minutes.

Figure- 4.Flowers (A.), dietary bread (B), and pickled fruit (C,D)using fruit elements capers 
This will increase the productivity of enterprises and increase the economic efficiency of production. The use of this method will reduce their total consumption, which makes the use of these natural additives economically feasible, given the relatively high cost of this product.

Ready-made samples of canned food, seeds, flower, leaves and stems and roots that can be exported from fruits and vegetables have been prepared and prepared for the treatment of various diseases in the pharmaceutical industry. the fatty acids and their compounds in the seeds of ripe fruits are equated. For example, in cultured cultures, $0.32 \%$ of routine, $150 \mathrm{mg} \%$ of vitamin C, R, E, $12 \%$ of sugar, $18-20 \%$ of flavonoids, $29-30 \%$ of glycosides, $36 \%$ of fat in fat, $25 \%$ in bubbles, 27 $-30 \%$ of iodine.

There is an increased activity of the immune system in the organisms used by Kappres products, which demonstrated resistance to external conditions and body activity. In patients who feed on seeds, white dots in the body disappeared due to the removal of spongy traumatoid, dental and nematode forms and active forms of lyophils.
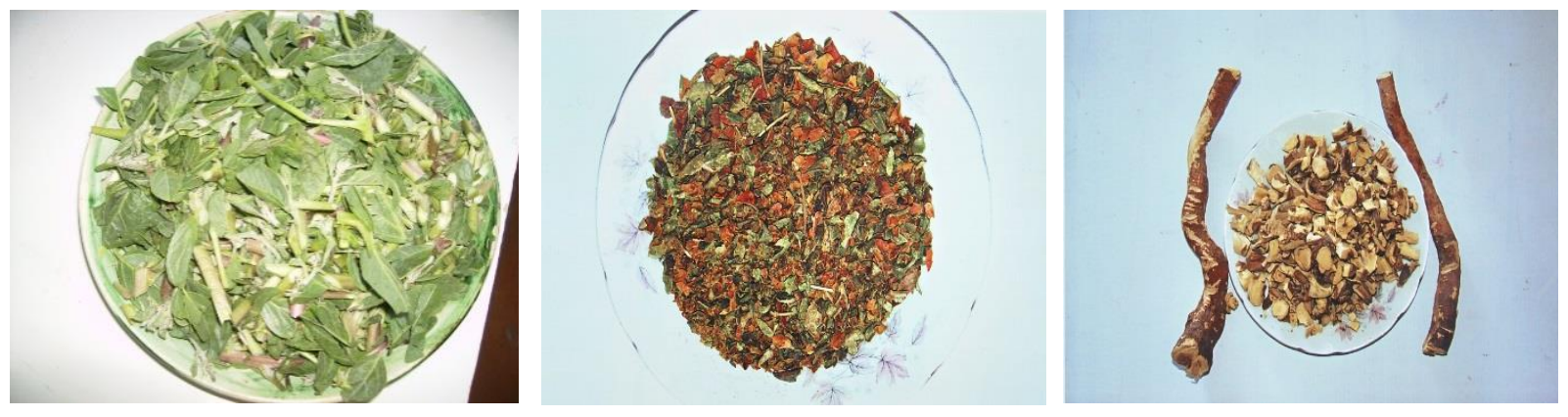

Figure- 5. Laboratory work on the preparation of various food and pharmaceutical products

In order to produce pickled canned capers, it is necessary to have a complete understanding of the chemical composition of the original raw material, canned product, changes in the production cycle and storage of canned food, as well as the equipment on which canned food is produced.

Analysis of the current level of organization of technological processes for processing agricultural products, including nontraditional wild raw materials, shows that the existing technology and equipment, with some adjustments, are suitable for the production of canned food. Like recipes for canned wild mountain onions "Anzur" and green nuts, preparation of raw materials for canning is required..

\section{LITERATURE}

1. Eshankulova N.T., Akhmedova Z.R. Biochemical properties of Capparis spinosaL. and its ecological aspects in the desert areas of Jizzakh region // News of the National University of Uzbekistan - Tashkent. 2013. № 4. 95-98 p.

2. Eshankulova N.T., Akhmedova.Z.R . Thermokserophyte-Capparisspinosa L and its distribution in the desert areas of Jizzakh region, as well as some biological aspects // Journal of Biology of Uzbekistan. Tashkent. 2015
3. EshonkulovaN.Capparisspinosa use for improvement of soil // The Science Advanced. USA. 2013.№3.-R.85-88.

4. Eshankulova N. T., Dildebaeva Z. S., Akhmedova Z. R., Halmurzaeva A. the Biological significance and cultivation of xylotrophicCapparisspinosa.L. in arid zones and their influence on the number of soil species.// "Auzyovskaya readings-11:" Kazakhstan on the way to knowledge toinnovative directions of development of science, education and culture»Proceedings of the International scientific and practical conference, Shymkent, 2012.

5. Eshankulova N.T. Capers materials for creating promising biotechnological food and pharmaceutical products / / proceedings of the conference "Problems of modern biology " IXCollection of proceedings of the International scientific and practical conference. Moscow. 2013.

6. Eshonkulova N. T. Importance of cultivation of Capparisspinosa L. in arid zones of Uzbekistan for development of desert lands and improvement of ecology // Proceedings of the international scientific and practical conference "Modern problems of biotechnology" Kazakhstan, 2016.

7. Griffith V. Vitamins, herbs, minerals, and nutritional supplements. Reference book / 
winter Griffith; Per. s Engl. K. Tkachenko. M.: Fair Press, -2002. - P. 40

8. EshonkulovaN.T., Merganov A. Biological properties, chemical composition and medical significance of the cultivar "Capparisspinosa" of the cultivar "Uzbekistan-20" // Scientific and technical journal of Fergana Polytechnic Institute-Fergana, 2014. №4

9. EshonkulovaN.,Merganov A. Capers (Kavar, Capparis spinosa) as a cultivated plant suited for steppe soils. // Proceedings of International conference the fermeres biologii, India, 2014.

10. Jacobs, M. 1964: The genus Capparis (Capparaceae) from the Indus to the Pacific. Blumea 12: 385-540.

11. Inocencio C, Alcaraz F, Calderon F, et al. 2002. The use of floral characters in Capparissect.Capparisto determine the botanical and geographical origin of capers. European Food Research and Technology, 214: 335-339.

12. Higton, R. N. \&Akeroyd, G. R. 1991: Variation in Capparisspinosa L. in Europe. - Bot. Joum.

13. Pruntova O. V., Sakhno O. N. Laboratory workshop on General Microbiology Methodological guide, Federal Agency for education, state educational institution of higher professional education, Vladimirsky

14. Polandova, R. D. Methods of activation of pressed and dried yeast at bakery enterprises / R. D. Polandova, I. K. Eletsky, A. S. Demidova [et al.]//Scientific and technical abstract collection. Series 27. Bakery, pasta, yeast industry. Overview information. - M.: Tsniiteipishcheprom.- 1984.- №11. - 28 p.

15. Zvyagintsev D. G. Methods of soil Microbiology and biochemistry. Moscow, 1991. $350 \mathrm{p}$

16. Matveeva, I. G. Belyavskaya. Biotechnological bases of bread preparation / I. V.-M.: Delhi print. -2001. - $150 \mathrm{p}$.

17. Ermakov A. I., Arasimovich V. A. and others. Methods of biochemical research of plants. - L.Kolos. - 1972. P-92-94

18. Vili A, Tao Wu, Sagdullaev B. T. Carbohydrates and lipids of the roots of Capparisspinosa / / Chemistry of natural compounds. 2006. P-178

19. Trili N, Nasri N, Saadaoui E, et al. 2009. Carotenoid and tocopherol composition of leaves, buds, and flowers of Capparisspinosa grown wild in Tunisia. Journal of Agricultural and Food Chemistry, 57: 5381-5385.

20. Suleiman, M.K., Bhat, N.R., Abdal, M.S., Jacob, S., Thomas, R.R., Al-Dossery, S., V Bellen, R. 2009. Germination studies of Capparisspinosa L.,
Propagation of Ornamental Plants, 9(1), 35-38.

21. Rhizopoulou S, Ioannidi E, Alexandredes N, et al. 2006. A study on functional and structural traits of the nocturnal flowers of Capparisspinosa L. Journal of Arid Environments, 66: 635-647. 